\title{
Torsional Strengthening of Low-Strength RC Beams with Post-Tensioned Metal Straps: An Experimental Investigation ${ }^{\dagger}$
}

\author{
Monthian SETKIT ${ }^{1,2}$, Thanongsak IMJAI ${ }^{1,2, *}$, Udomvit CHAISAKULKIET ${ }^{3}$, \\ Reyes GARCIA $^{4}$, Komsan DANGYEM ${ }^{1}$, Katipoj SANUPONG ${ }^{1}$ and \\ Weerasit CHAMNANKIT ${ }^{1}$
}

\author{
${ }^{1}$ School of Engineering and Technology, Walailak University, Nakhon Si Thammarat 80160, Thailand \\ ${ }^{2}$ Center of Excellence in Sustainable Disaster Management, Walailak University, \\ Nakhon Si Thammarat 80160, Thailand \\ ${ }^{3}$ Department of Civil Engineering, Rajamangala University of Technology Rattanakosin, \\ Nakhon Pathom 73170, Thailand \\ ${ }^{4}$ School of Engineering, The University of Warwick, Coventry, UK
}

('Corresponding author's e-mail: thanongsak.im@wu.ac.th)

Received: 1 June 2019, Revised: 26 June 2020, Accepted: 8 July 2020

\begin{abstract}
This article investigates the behaviour of low-strength reinforced concrete beams under pure torsion with and without strengthening. Four beams were cast and tested in torsion: i) a control beam without vertical reinforcement, ii) two beams with internal stirrups designed for shear and torsion demands using different stirrup spacing (50 and $100 \mathrm{~mm}$ ), and iii) a beam having steel stirrups with a spacing of $100 \mathrm{~mm}$ strengthened using high ductile post-tensioned metal straps (PTMS). The main objective of the PTMS strengthening solution was to investigate the enhancement of torsional strength confined along the beam. The failure modes, torsional capacities, rotation, and strengthening performance in torsion are discussed in in this study. The experimental results indicate that the PTMS improved the cracking torque capacity by up to $15 \%$ compared to the control beam. Moreover, the PTMS also increased the ultimate torque by up to $19 \%$ compared to the unstrengthened beam. Current code equations to predict the torsional capacity of $\mathrm{RC}$ beams are also compared with the experimental results. It is found that the predictions obtained by current ACI equation gives a good agreement and yield in general conservative values compared to the experimental ones.
\end{abstract}

Keywords: Torsional strengthening, Low strength concrete, Post-tensioned metal straps, Active confinement, Torsion, Steel straps, Strengthening

\section{Introduction}

Many existing reinforced concrete (RC) structures around the world are in need of repair/rehabilitation due to initial design errors, construction mistakes, use of poor quality materials, change of the use of the structure use, update of design codes, environmentally induced degradation, increase in service loads, among others. In many cases, there are two possible solutions i)

†Presented at the $2^{\text {nd }}$ International Symposium on Construction Innovation Research \& PhD Symposium: July 18-19, 2019. 
repair/strengthening and ii) demolition/reconstruction [1]. In most structures, repairing and strengthening is preferred as this is often the most cost-effective solution. This is particularly true in many rural areas of developing countries, where RC is produced by manual mixing and casting thus leading to a low-strength concrete. Another issue is that many elements lack an adequate detailing of reinforcement. Accordingly, many RC members have insufficient torsional capacity. Normally, the torsion strength of existing concrete members can be enhanced by methods such as sectional enlargement combined with additional transverse shear reinforcement. Another option is to apply externally bonded reinforcement (confinement) such as steel plates or fiber reinforced polymers (FRP). The torsional strength of RC members can also be enhanced by applying axial compression along the member through post-tensioning [1-3]. Although many of these solutions have been used in the past, FRPs have proven to be more popular compared to others due to ease of installation, high strength to weight ratio, and durability to exposed environment issues. However, the relatively high cost of the material and the need to hire specialised contractors for installation, which in turn may limit the use of FRP solution in developing countries [4-9]. Moreover, most of the existing strengthening solutions can only apply passive confinement to the RC elements.

Pioneering research by Frangou et al. [10] and later modified by Imjai et al. [11,12] led to the development of a novel strengthening technique of RC members using highly-ductile metal confining straps. The Post-tension Metal Strapping (PTMS) has previously proven to be effective at increasing both stiffness and capacity of concrete members [10-15]. Moreover, PTMS provides active confinement to concrete members, thus increasing their ductility and capacity before applying load. Compared to traditional steel/concrete and FRP confinement, PTMS has advantages such as ease and speed of application, low material cost and ease of quickly removing/replacing damaged straps and clip locks. As no adhesives or sophisticated equipment is used, PTMS strengthening is also expected to provide costeffective retrofitting solutions due to lower material and labour costs [11]. Although PTMS has been proven to increase flexural, shear and axial capacity of RC elements [13-17], little attention have been paid to its applicability in torsional strengthening of low strength RC beams in term of experimental research compared to the current code provisions [18].

This article fills the gap in the experimental area by investigating the torsional behaviour of lowstrength concrete beams strengthened with PTMS under pure torsion. The main objective of the study is to assess the effectiveness and feasibility of the PTMS at improving torsional behaviour.

\section{Experimental programme}

\section{Test matrix and reinforcement details}

The experimental programme included tests on four $\mathrm{RC}$ beams with a rectangular cross-section of $250 \times 150 \mathrm{~mm}^{2}$, a span of $2000 \mathrm{~mm}$, and a moment arm of $500 \mathrm{~mm}$ (see Table 1 and Figure 1a). The tested beams had internal steel flexural and shear reinforcement. They were designed according to the specifications of the current ACI Building code [18]. Three $\phi 12 \mathrm{~mm}$ steel bars $\left(f_{y}=392 \mathrm{MPa}\right)$ were used as flexural bottom reinforcement in all beam specimens, leading to a flexural reinforcement ratio $\rho=1.03$ $\%$. The provided flexural reinforcement ratio was larger than the ACI minimum requirement, and approximately equal to $96 \%$ of the ACI maximum longitudinal reinforcement ratio [18]. The top reinforcement for specimens B1 and B2 in the compression zone (outside the midspan) consisted of two $\phi 9 \mathrm{~mm}$ bars $\left(f_{y}=235 \mathrm{MPa}\right.$ ), were also used to hold the vertical shear stirrups (except for B3, three $\phi 9 \mathrm{~mm}$ bars were used to increase torsional capacity from longitudinal reinforcement). Control specimen B1 was cast without vertical reinforcement (Figure 1b). whereas transverse steel reinforcement (two legs stirrups) of $\phi 9 \mathrm{~mm}$ at a spacing of 100 and $50 \mathrm{~mm}$ were provided for specimens B2 (Figure 1c) and B3 (Figure 1e), respectively. Specimen B2-ST was strengthened using the PTMS technique by adding metal straps (Figure 1d), as explained later. The straps had a cross section of $32 \times 0.9 \mathrm{~mm}^{2}$ and were fixed using a pneumatic strapping tool model PT-52 at a pressure of 8 bars (116 psi). The highly ductile metal straps were coated with epoxy and was wax-finished. The elongation at break of the metal straps was $9.6 \%$, whereas their average yield stress and ultimate stress were 850 and $950 \mathrm{MPa}$, respectively, as determined from six direct tensile tests (Figure 1c). 


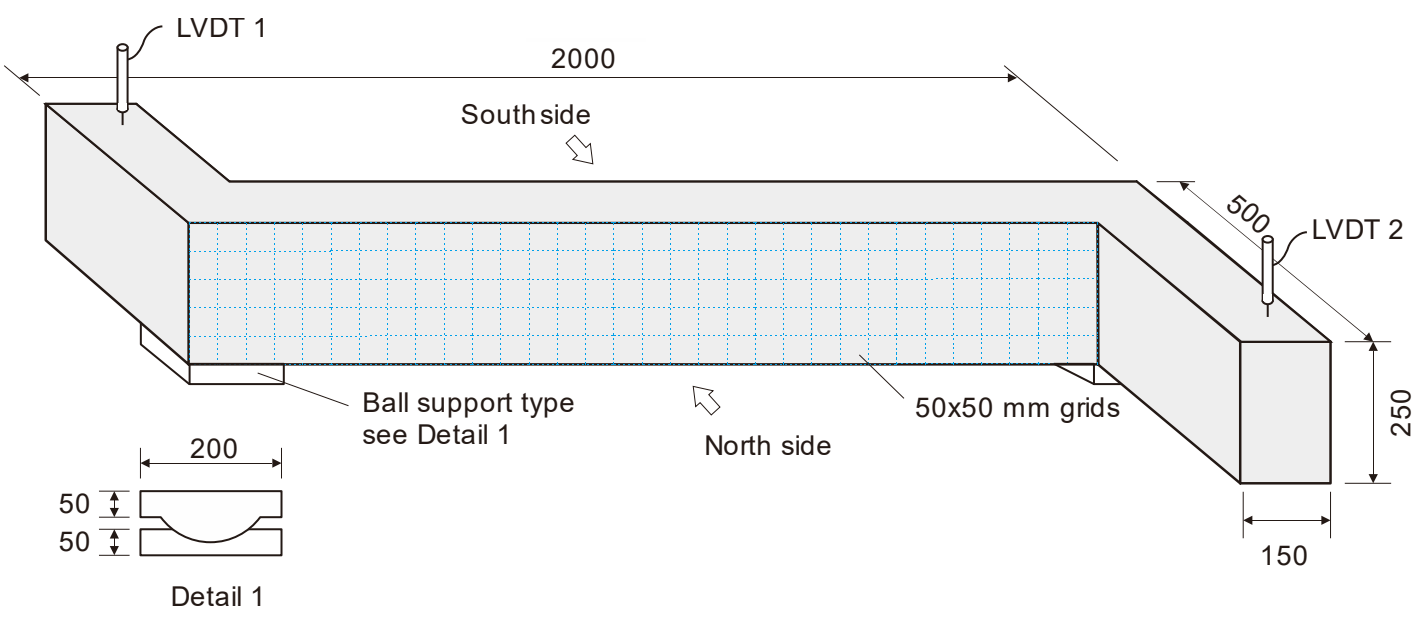

(a) Dimension of the tested specimens

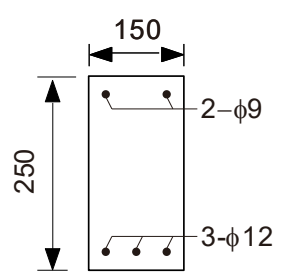

(b) Beam B1

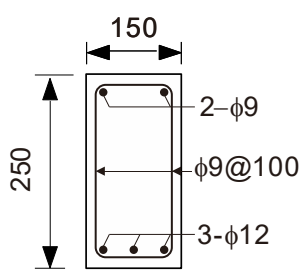

(c) Beam B2

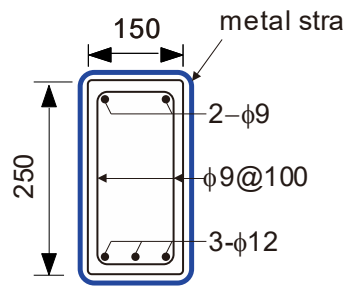

(d) Beam B2-ST

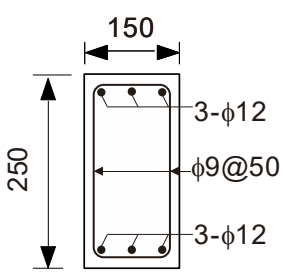

(e) Beam B3

Figure 1 Cross-section details of tested beam specimens (unit in millimetres).

Table 1 Details of the beam specimens.

\begin{tabular}{|c|c|c|c|c|}
\hline \multirow[b]{2}{*}{ Specimen ID } & \multicolumn{2}{|c|}{ Transverse reinforcement } & \multirow[b]{2}{*}{$\frac{A_{P T M S}}{S_{P T M S}}$} & \multirow[b]{2}{*}{$\rho_{w, t o t}(\%)$} \\
\hline & $\rho_{w}(\%)$ & $\frac{A_{v}+2 A_{t}}{s}$ & & \\
\hline B1 & 0 & 0 & - & 0 \\
\hline B2 & 0.848 & 1.272 & - & 0.848 \\
\hline B2-ST & 0.848 & 1.272 & 1.80 & 0.943 \\
\hline B3 & 1.696 & 2.545 & - & 1.696 \\
\hline
\end{tabular}

Note: $\rho_{w}$ is the ratio of transverse reinforcement ratio provided by steel stirrups, $\rho_{w, t o t}$ is the ratio of total transverse reinforcement ratio provided by steel stirrups and metal straps, $A_{v}$ is the cross-sectional area of steel stirrups design for shear demand, $A_{t}$ is the cross-sectional area of steel stirrups design for torsion demand, $s$ is the spacing of steel stirrups, $A_{P T M S}$ is the cross-sectional area of metal straps, $s_{P T M S}$ is the spacing of metal straps.

\section{Concrete properties}

A single batch of Ordinary Portland Cement (OPC type I) was used to cast the beams (Figure 2), as well as cylinder and prism specimens. The mix design for the concrete is shown in Table 2. Crushed granite stone with a maximum size of $10 \mathrm{~mm}$ was used as coarse aggregate, and river sand was used as 
fine aggregate. The water-to-cement ratio (w/c) was 0.79 with a slump of $75 \mathrm{~mm}$. The compressive strength of concrete was obtained from $150 \times 150 \times 150 \mathrm{~mm}^{3}$ cubes BS EN 12390-3 [19] and $150 \times 300 \mathrm{~mm}^{2}$ cylinders according to ASTM C39 [20]. The indirect tensile splitting strength $\left(f_{t}=1.4 \mathrm{MPa}\right)$ was determined from tests on $150 \times 300 \mathrm{~mm}^{2}$ cylinders according to ASTM C439 [21]. The flexural strength $\left(f_{b}\right.$ $=1.9 \mathrm{MPa}$ ) was obtained from three prisms of $100 \times 100 \times 500 \mathrm{~mm}^{3}$ tested in four-point bending according to BS EN 12390-5 [22]. Table 3 summarises the laboratory test result of concrete properties.

Table 2 Mix proportion of concrete used to cast beam specimens.

\begin{tabular}{|c|c|c|c|c|c|}
\hline \multicolumn{4}{|c|}{ Mix proportion $\left(\mathrm{kg} / \mathrm{m}^{3}\right)$} & \multirow{2}{*}{ w/c ratio } & \multirow{2}{*}{$\begin{array}{c}\text { Slump } \\
(\mathrm{mm})\end{array}$} \\
\hline Cement & Coarse aggregate & Sand & Water & & \\
\hline 248 & 1118 & 755 & 198 & 0.79 & 75 \\
\hline
\end{tabular}

Table 3 Properties of concrete.

\begin{tabular}{lcccc}
\hline $\begin{array}{c}\text { Statistical } \\
\text { values }\end{array}$ & $\begin{array}{c}\text { Cube } \\
\text { Compressive strength }\end{array}$ & $\begin{array}{c}\text { Cylinder } \\
\text { Compressive strength }\end{array}$ & $\begin{array}{c}\text { Tensile } \\
\text { strength }\end{array}$ & $\begin{array}{c}\text { Flexural } \\
\text { Strength }\end{array}$ \\
\hline Mean $(\mathrm{MPa})$ & 18.8 & 15.4 & 1.4 & 1.9 \\
Std. Dev. (MPa) & 3.1 & 2.8 & 0.5 & 0.3 \\
Sample (N) & 6 & 6 & 6 & 6 \\
Min. & 17.2 & 14.1 & 1.3 & 1.4 \\
Max. & 21.5 & 18.9 & 1.6 & 2.1 \\
\hline
\end{tabular}

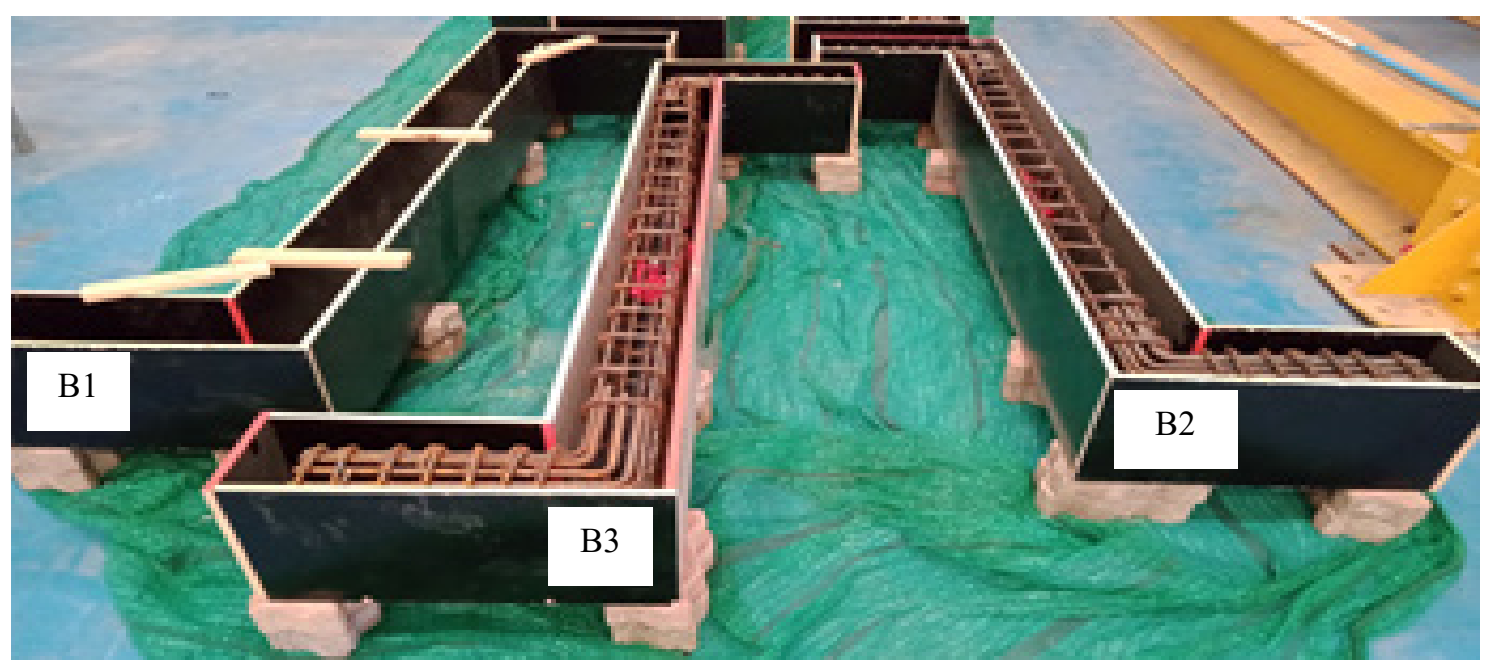

Figure 2 Beams and reinforcement before casting.

Test setup and instrumentation

The test setup on the Universal Testing Machine (maximum capacity of 1,000 kN) subjected the beams to pure torsion, as shown in Figure 3. A diagonal steel spreader beam with H-section transferred a couple of vertical loads on the lever arm of $500 \mathrm{~mm}$ at the beams' ends. A twist was created at both beams' ends, with the middle part of the beam specimen subjected to pure torsion. The RC beam was supported by ball supports at both ends, as shown in Figure 1a. Two Linear Variable Displacement Transducers (LVDTs) recorded vertical deflections at an interval of $0.001 \mathrm{~mm}$, which were then 
converted to angle of twist. As each lever arm was superimposing with equal force, the torque was calculated as the product of the applied force and the perpendicular distance. In the testing programme, the load was applied in increments of approximately $5 \mathrm{kN}$. At each loading step, cracks were marked, and the width of selected cracks was measured using a hand-held micrometre every $1-2 \mathrm{kN}$, depending on the expected torsional capacity of the beam. Crack characteristics such as crack width/spacing and orientation were marked on the surface of beam specimens for beams B1, B2 and B3. In the case of B2ST, full crack patterns were observed closely after the removal of PTMS, i.e. after failure of the specimen. To identify the faces of the beam where cracks formed, each beam had a North and a South side.

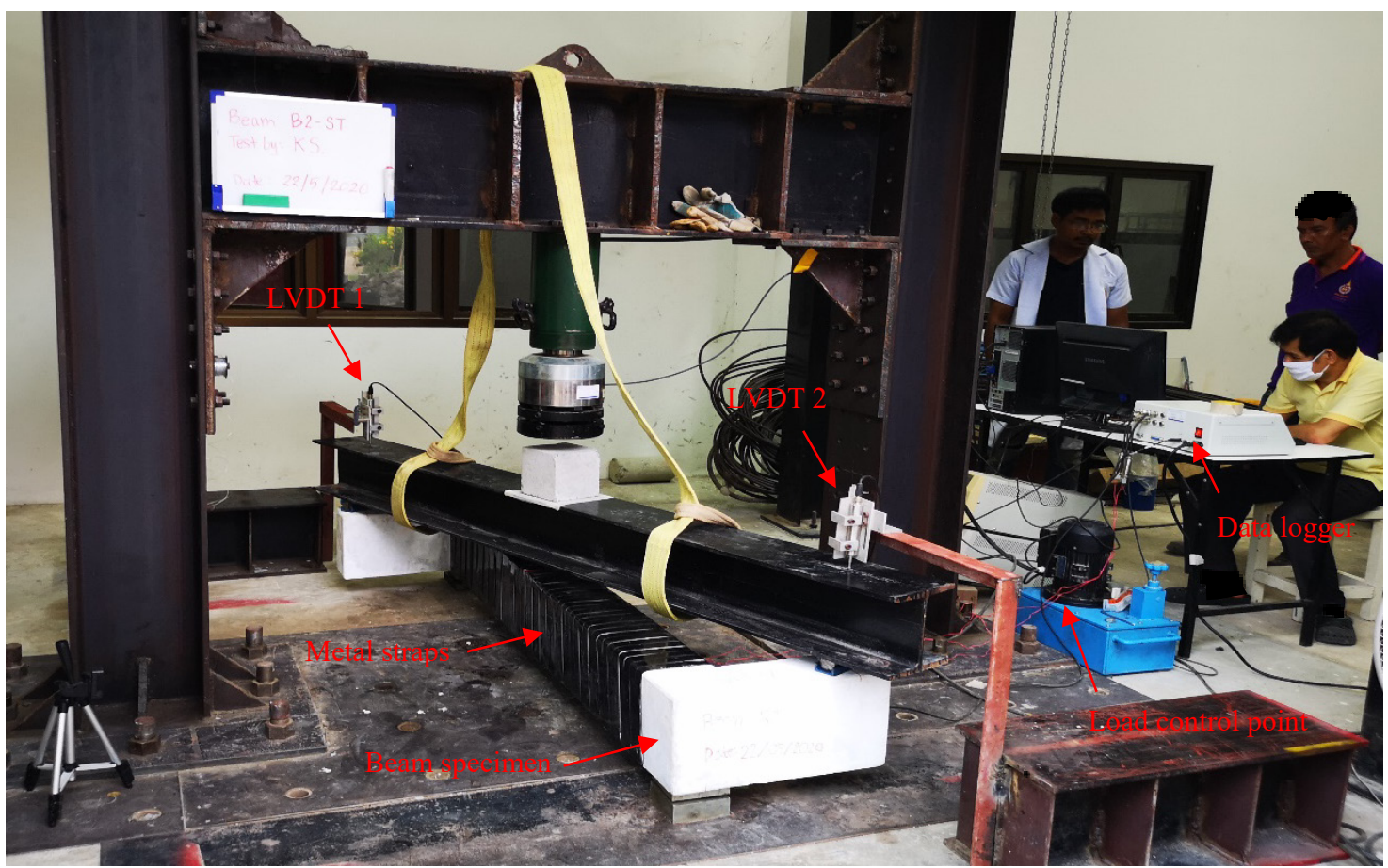

Figure 3 Test setup and instrumentation showing LVDT measurements, load control point, and data acquisition system.

\section{Torsional strengthening using PTMS}

The PTMS technique uses ductile high-strength steel straps post-tensioned around RC elements using strapping tools as those used in the packaging industry. Metal straps are commercially available in various thicknesses, widths, and strengths. The ease of handling and strengthening objective determines the strap dimensions. The metal strap used in this study had a yield strength of $850 \mathrm{MPa}$, with an ultimate strength of $900 \mathrm{MPa}$. Two types of tensioning machines exist i) pneumatic, in which the tension force is regulated accurately by applied air/hydraulic pressure, or ii) manual, in which the tension force is controlled by the operator. Figure 4 illustrates the installation of metal straps on the specimen B2-ST. The installation began by placing a metal strap on the clip lock as shown in Figure 4a. Then, the strap was engaged to the pneumatic strapping tool used in this study (Figure $4 \mathbf{b}$ ). Finally, a tension force was applied to the metal straps along the beam as shown in Figure 4c and 4d. The adopted strengthening solution for beam B2-ST used $32 \times 0.9 \mathrm{~mm}^{2}$ straps around the cross section at a spacing $32 \mathrm{~mm}$ centre-tocentre. Accordingly, the PTMS was installed continuously (i.e. without any gaps) around the whole effective torsional length of the specimen. 

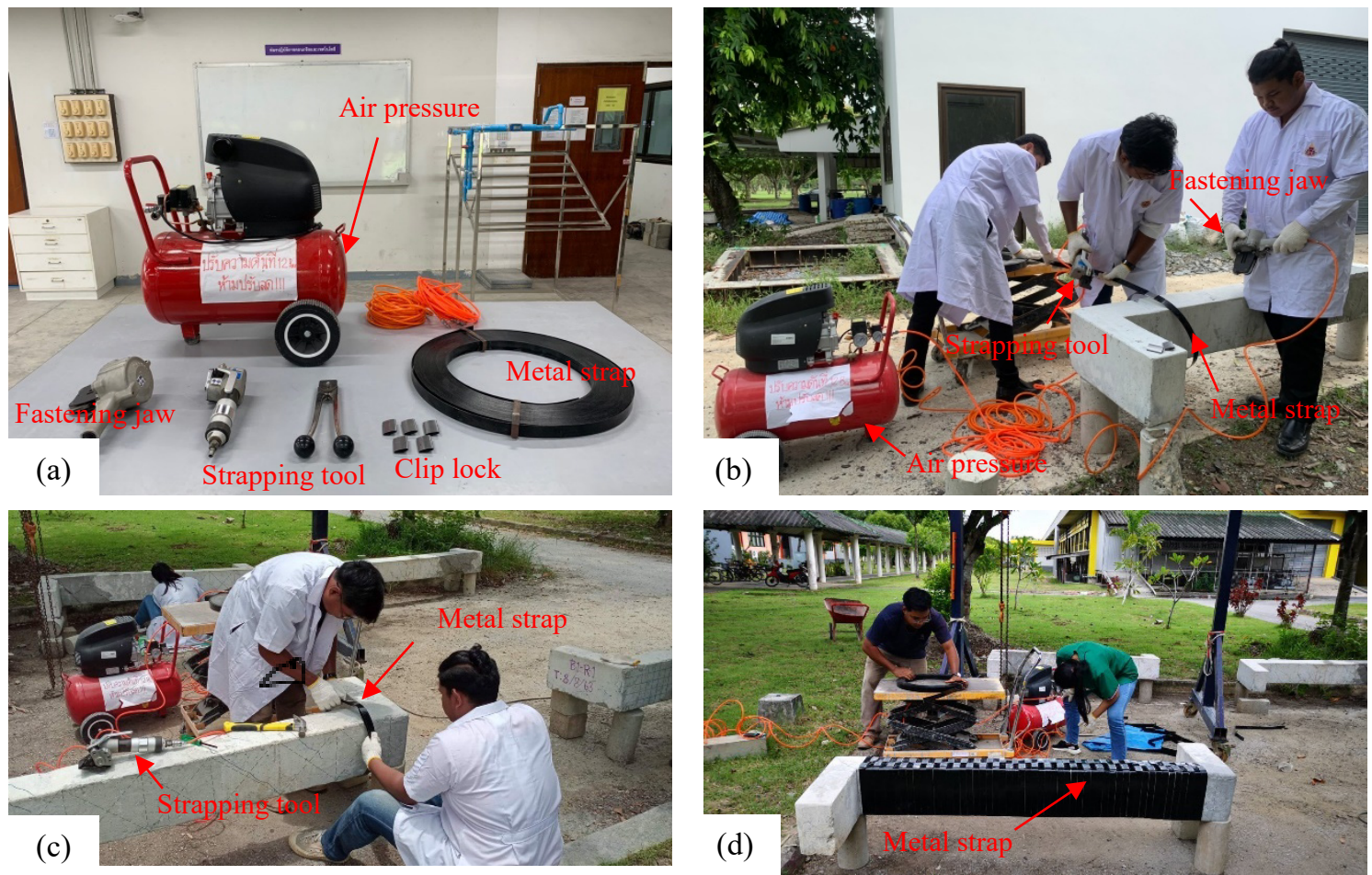

Figure 4 Torsional strengthening procedure: (a) placing a metal strap on the clip lock (b) engaging the strap to the pneumatic strapping tool, (c) applying a tension force to the metal straps along the beam, and (d) beam ready to test.

\section{Test results and discussions}

\section{Torsional capacity and failure behaviour}

Table 3 summarises the torsional moment and angle of twist for the controlled beam (B1), torsionally-designed beam (B2 and B3), and PTMS-strengthened beam B2 (B2-ST). The average torsional moment for all beams at first crack was found to be $2.36 \mathrm{kN}-\mathrm{m}$ at an average angle of twist of 0.0084 degrees. The ultimate torque taken by the control beam B1 was $2.20 \mathrm{kN}-\mathrm{m}$ at an angle of twist of 0.0043 degrees. For specimen B2 (designed with smaller amount of transverse reinforcement), the $1^{\text {st }}$ crack appeared at about $2.28 \mathrm{kN}-\mathrm{m}$ at an angle of twist was 0.0046 degrees, approximately. At the ultimate torque of $2.77 \mathrm{kN}-\mathrm{m}$, the twisting angle was about 0.035 degrees. For specimen B3, designed with torsional reinforcement, the $1^{\text {st }}$ crack appeared at about $2.46 \mathrm{kN}-\mathrm{m}$ at an angle of twist was 0.024 degrees approximately. At the ultimate torque of $5.39 \mathrm{kN}-\mathrm{m}$, the twisting angle was about 0.091 degree. Cracking in B2-ST appeared at about $2.51 \mathrm{kN}-\mathrm{m}$ at an angle of twist of 0.0038 degree, with an ultimate torque of $3.31 \mathrm{kN}-\mathrm{m}$ at a twisting angle of 0.046 degrees. It was also observed that when specimen B2 was strengthened by PTMS, the cracking torque was improved by up to $10 \%$ compared to B2. Moreover, the ultimate twist angle of B2-ST was $31 \%$ higher than that of B2. This indicates that the PTMS strengthening solution was highly effective at improving the torsional strength and deformation capacity of beam B2-ST.

The toughness of each specimen was determined by the area of torque and twist angle after the first crack. The results in Table 3 indicate that specimen B3 (designed with sufficient torsional reinforcement) had the highest toughness $=415 \mathrm{kNm} \cdot \operatorname{deg} \times 10^{-4}$ ), whereas the control specimen (B1) exhibited the lowest toughness $\left.=49 \mathrm{kN}-\mathrm{m} \cdot \operatorname{deg} \times 10^{-4}\right)$. It is also noted that the strengthened specimen B2-ST improved the toughness of the beam $\left(210 \mathrm{kNm} \cdot \operatorname{deg} \times 10^{-4}\right)$ compared to the unstrengthen section B2 $\left(207 \mathrm{kNm} \cdot \mathrm{deg} \times 10^{-4}\right)$. 
These results further confirm the effectiveness of the PTMS strengthening solution at improving the torsional behaviour of beam B2-ST.

Table 3 Summary of experimental results.

\begin{tabular}{ccccccc}
\hline $\begin{array}{c}\text { Beam } \\
\text { specimen }\end{array}$ & $\begin{array}{c}\text { Cracking } \\
\text { torque } \\
(\mathbf{k N}-\mathbf{m})\end{array}$ & $\begin{array}{c}\text { Crack twist } \\
\text { angle } \\
(\text { Degree) }\end{array}$ & $\begin{array}{c}\text { Ultimate } \\
\text { Torque }\left(\mathbf{T}_{\mathbf{u}}\right) \\
(\mathbf{k N}-\mathbf{m})\end{array}$ & $\begin{array}{c}\text { Ultimate twist } \\
\text { angle } \\
(\mathbf{D e g r e e})\end{array}$ & $\mathbf{T}_{\mathbf{u}} / \mathbf{T}_{\mathbf{u}, \mathbf{B} 1}$ & $\begin{array}{c}\text { Toughness } \\
(\mathbf{k N m . d e g .} \\
\left.\times \mathbf{1 0}^{-4}\right)\end{array}$ \\
\hline B1 & 2.19 & 0.00096 & 2.20 & 0.00432 & 1.00 & 49.27 \\
B2 & 2.28 & 0.00466 & 2.77 & 0.03540 & 1.25 & 207.86 \\
B2-ST & 2.51 & 0.00384 & 3.31 & 0.04650 & 1.50 & 210.80 \\
B3 & 2.46 & 0.02437 & 5.39 & 0.09168 & 2.45 & 415.55 \\
\hline
\end{tabular}

Figure 5 compares the torsional moment at first crack and the ultimate torsional moment of the tested beams. Linear elastic behaviour was initially observed for all specimens, then followed by a large increase in the twist angle with gradually increasing in load until failure. As expected, the addition of PTMS strengthening did not modify significantly the initial stiffness of beam B2-ST. For the control beam B1, the cracking torque appeared at the North side and later progressed to the other three faces with a crack orientation of about 25 degrees (see Figure 6a). For beam B2, the cracking torque appeared at the North side and progressed to the other three faces with a crack orientation of about 42 degrees (see Figure 6b). For beam B3, a crack orientation was about 38 degrees (Figure 6c). The post-cracking stiffnesses gradually softened with increased torque up to failure. A notable increase of cracking strength (by up to $15 \%$ ) was observed in the strengthened beam (B2-ST) compared to other specimens.

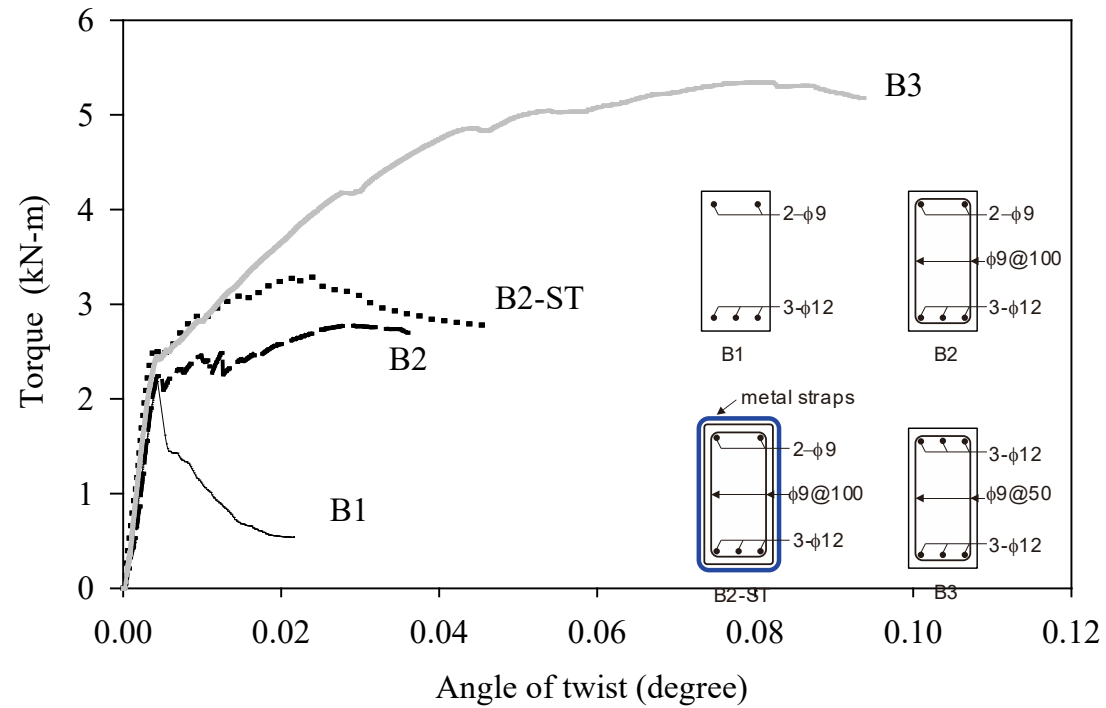

Figure 5 Torsional moment versus twist angle relationships. 

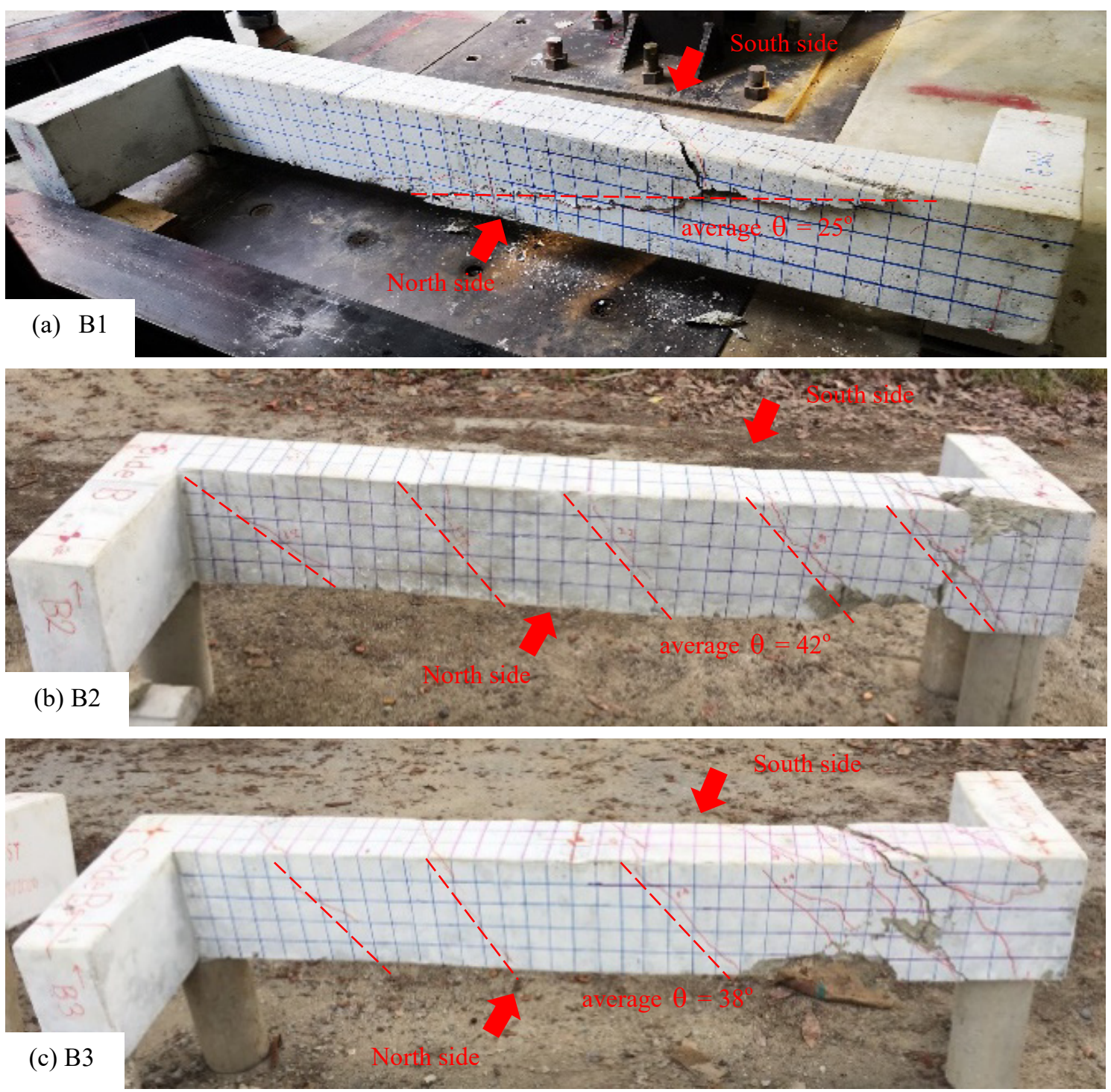

Figure 6 Failure and crack patterns of unstrengthen beams (B1-B3).

\section{Crack behaviour}

The crack behaviour of the beam specimens was monitored closely during testing. As the applied load increased, the crack paths were marked at each load step on the front face of the specimen. The crack widths were also measured using an optical microscope with an accuracy of $0.002 \mathrm{~mm}$. Significant differences in the torsional behaviour of the specimens B2 and B3 were observed. Specimen B3 with adequate torsional designed transverse reinforcement exhibited higher cracking and ultimate torque compared to the other beams. However, the strengthened beam B2-ST had a higher cracking torque compared to B3. This is due to the fact that the actively confined metal strap enhanced the concrete cracking under torsional loads. When the $1^{\text {st }}$ crack occurred, the effect of confinement improved the ultimate torque by up to $19 \%$ compared to the unstrengthen section (B2). The detail of the crack pattern for specimen B2-ST was closely investigated after the removal of PTMS (see Figures 7(a) - 7(b)). 
It was observed that the $1^{\text {st }}$ cracks formed at the South face and then progressed to the top and bottom faces, while the cracks significantly widened with increasing torque with a crack orientation of about 40 degrees (see Figure 7b). The PTMS strengthening produced stiffer post-cracking responses compared to its companion beam (B2). For specimen B3, the post-cracking stiffnesses was higher than the post cracking stiffnesses of B1. This can be attributed to the contribution of the torsional-designed transverse steel reinforcement in carrying the additional torque.
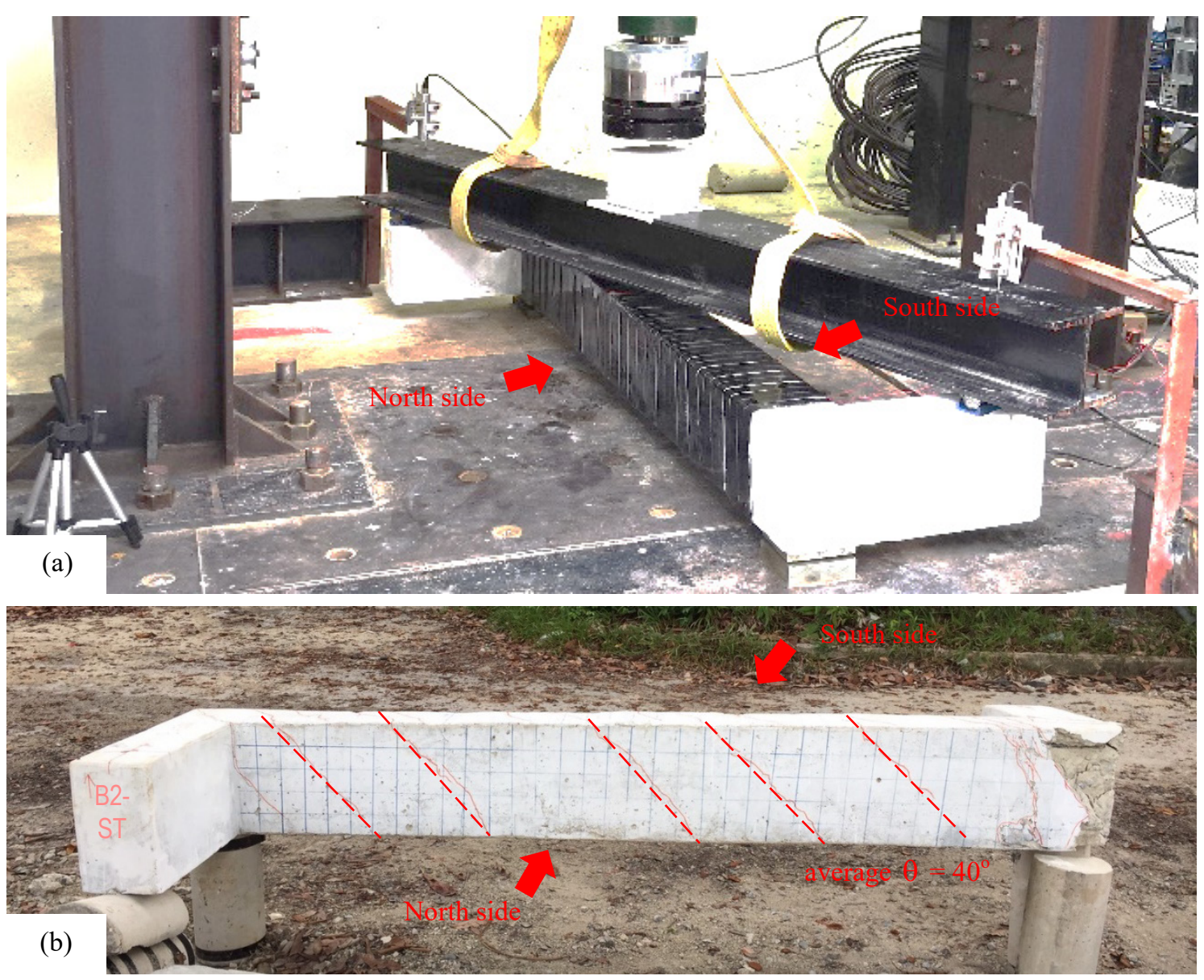

Figure 7 Failure and crack patterns of strengthened beam (B2-ST); (a) failure of specimen B2-ST and (b) crack pattern of specimen B2-ST after removal of metal straps.

\section{Effect of transverse reinforcement and code predictions}

Figure 8 presents the comparison of experimental cracking and the ultimate torques for different total transverse reinforcement provided. As seen in the figure, the concrete beam with PTMS had higher cracking torque compared to others (see also Figure 9). This is attributed to the addition of PTMS to specimen B2-ST, thus resulting in an increase of the amount of total transverse reinforcement $\left(\rho_{W, \text { TOT, }}\right)$ to $0.943 \%$. This in turn led to an increase in both cracking and ultimate torques by up to 15 and $50 \%$, respectively (Figure 9). According to the ACI 318-19 [18], the cracking torsional strength $\left(T_{c r}\right)$ can be calculated as: 


$$
T_{c r}=0.33 \sqrt{f_{c}^{\prime}}\left(\frac{A_{c p}^{2}}{p_{c p}}\right)
$$

where $f_{c}^{\prime}$ is the cylinder compressive strength of concrete in $\mathrm{MPa}, A_{c p}$ is the area enclosed within outer perimeter of concrete cross section in $\mathrm{mm}^{2}$, and $P_{c p}$ is the outside perimeter of concrete cross section in $\mathrm{mm}$.

The total ultimate torsional strength of reinforced concrete beams $\left(T_{n}\right)$ included in ACI 318 [18] is based on the space truss analogy. This approach is used here to calculate the torsional strength of the transverse steel reinforcement $\left(T_{n, S}\right)$ and metal straps $\left(T_{n, P T M S}\right)$ to compare such value to the experimental values.

$$
\begin{aligned}
& T_{n}=T_{n, s}+T_{n, P T M S} \\
& T_{n, s}=\frac{2 A_{o} A_{t} f_{y t}}{s_{s}} \cot \theta \\
& T_{n, P T M S}=\frac{2 A_{o} A_{P T M S} f_{y P T M S}}{s_{P T M S}} \cot \theta
\end{aligned}
$$

where $A_{t}$ is area of one leg of closed steel stirrup resisting torsion within spacing $s_{S}, A_{P T M S}$ is area of one leg of metal straps resisting torsion within spacing $s_{P T M S}, f_{y t}$ is the specified yield strength of the transverse steel reinforcement, $f_{y P T M S}$ is the yield strength of the metal straps, $A_{o}$ is the gross area enclosed by the shear flow path (which can be taken equal to $0.85 A_{o h}$ ), $A_{o h}$ is the area enclosed by the centre of stirrups, and $\theta$ is the angle of compression struts.

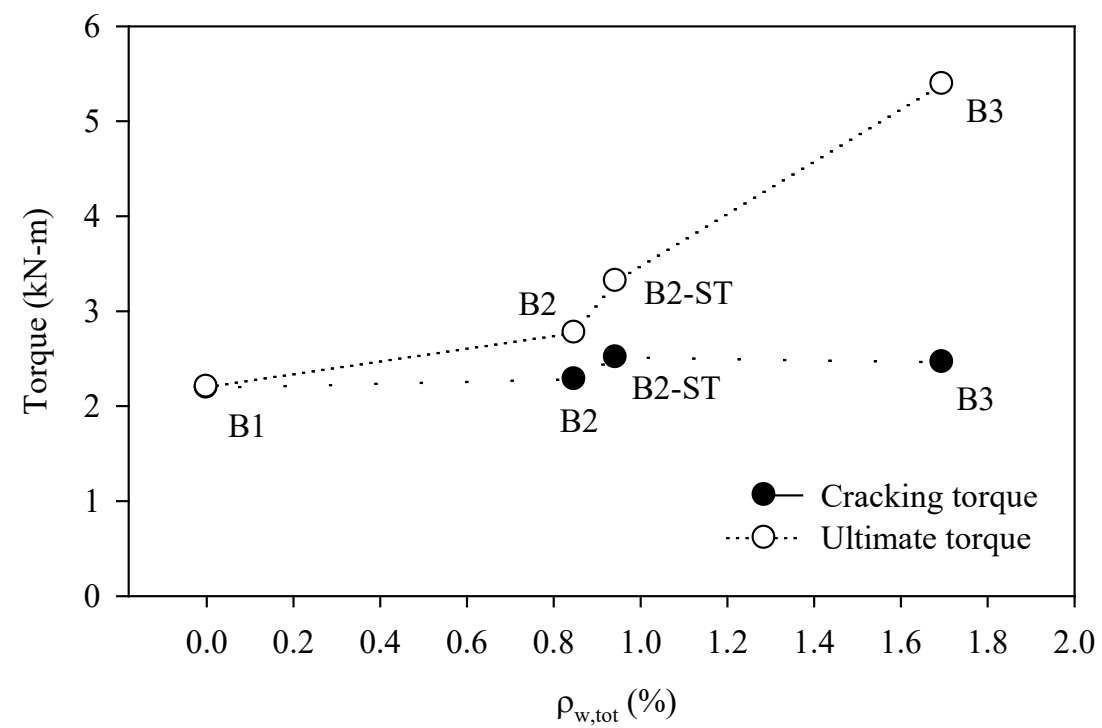

Figure 8 Comparison of experimental cracking and ultimate torques for different total transverse reinforcement provided. 
Table 4 compares the experimental (Exp.) cracking and ultimate torsional strength values and the ACI predictions (Pre.). As it is shown in Figure 9, the ACI predicts a higher result for beams B1 and B2. In the case of the strengthened beam B2-ST and beam B3, the ACI equation gives a conservative prediction. Overall, the mean $($ Exp./Pre. $)=1.03$ with SD. $=0.06$ indicates that the ACI equation provides good estimations for $T_{c r}$. In the case of ultimate torsional strength, when the total amount of transvers reinforcement (i.e. $\left.\rho_{W, T O T}\right)$ is used in the calculation, the mean $($ Exp./Pre.) $=1.10$ with SD. $=0.11$. These results indicate that the current $\mathrm{ACI}$ equation could be used to predict the ultimate torsional strength of concrete members with a good agreement between experimental and prediction values. However, given the limited number of specimens tested in this study, further research should be conducted to verify the validity of the equations to predict the torsional strength of beams strengthened with different PTMS configurations.

Table 4 Comparisons of cracking and ultimate torque between experimental and code predictions.

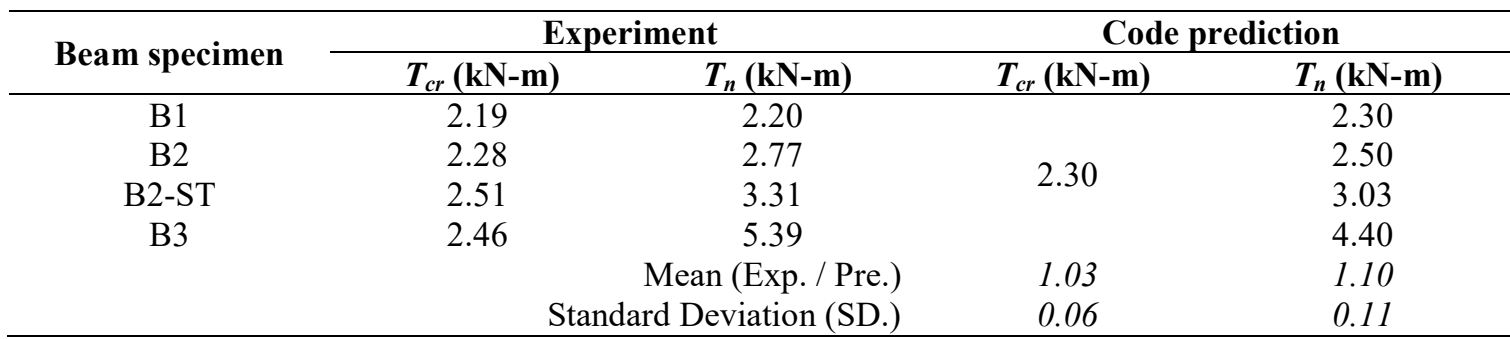
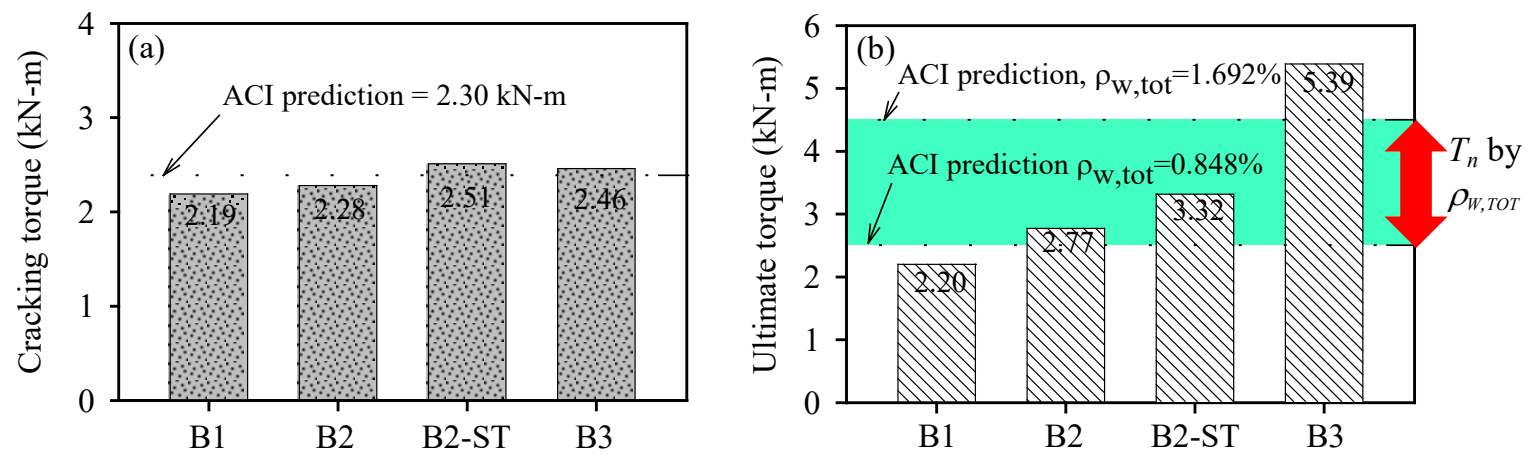

Figure 9 Comparison of experimental cracking and ultimate torques for tested beam specimens.

\section{Conclusions}

This article investigated the behaviour of low-strength reinforced concrete beams under pure torsion with and without PTMS strengthening. From the results presented in this article, the following conclusions are drawn:

- The PTMS strengthening solution improved the torsional strength of beam B2-ST. The experimental results indicated that the PTMS improved the cracking torque by up to $15 \%$ compared to the control beam B1. Moreover, the PTMS also increased the ultimate torque by up to $19 \%$ compared to the unstrengthen section. 
- The ultimate twist angle of B2-ST was $31 \%$ higher than that of B2, thus confirming that the PTMS strengthening solution was very effective at improving the torsional deformation capacity of such beam.

- The predictions obtained by the current ACI equation agree well (on the conservative side) with the experimental results. However, given the limited number of specimens tested in this study, further research should be conducted to verify the validity of the equations at predicting the torsional strength of beams strengthened with different PTMS configurations.

\section{Acknowledgements}

The authors express their appreciation to Walailak University for funding the work through the research grant No. WU63217. This project is funded by National Research Council of Thailand (NRCT5RSA63019-04). Special thanks are also extended to Ms. Natthaporn Kanthapradit for casting the beam specimens at Rajamangala University of Technology Rattanakosin.

\section{References}

[1] MG Grantham. Concrete Repair: A Practical Guide. CRC Press, 2011, p. 328.

[2] H Moghaddam, M Samadi, K Pilakoutas and S Mohebbi. Axial compressive behaviour of concrete actively confined by metal strips; part A: Experimental study. Mater. Struct. Constr. 2010; 43, 1369-81.

[3] AF Daly and W Witarnawan. Strengthening of bridges using external post-tensioning. In: Proceedings of the Conference of Eastern Asia Society for Transportation Studies. Seoul, Korea, 1997.

[4] JG Teng, JF Chen, ST Smith and L Lam. FRP: Strengthened RC Structures. Wiley-VCH, 2002, p. 266.

[5] T Imjai and R Garcia. Performance of damaged RC beams repaired and/or strengthened with FRP sheets: An experimental investigation. In: Proceedings of the $24^{\text {th }}$ Australasian Conference on the Mechanics of Structures and Materials. Perth, Western Australia, 2016.

[6] T Imjai and M Guadagnini. Shear strengthening of cracked RC structures under service loading condition-a case study. In: Proceedings of the $12^{\text {th }}$ International Symposium on Fiber Reinforced Polymers for Reinforced Concrete Structures \& the $5^{\text {th }}$ Asia-Pacific Conference on Fiber Reinforced Polymers in Structures Joint Conference. Nanjing, China, 2015.

[7] A Ghobarah, MN Ghorbel and SE Chidiac. Upgrading torsional resistance of reinforced concrete beams using fiber-reinforced polymer. J. Compos. Constr. 2002; 6, 257-63.

[8] MY Alabdulhady and LH Sneed. Torsional strengthening of reinforced concrete beams with externally bonded composites: A state of the art review. Constr. Build. Mater. 2019; 205, 148-63.

[9] G Al-Bayati, R Al-Mahaidi, MJ Hashemi and R Kalfat. Torsional strengthening of RC beams using NSM CFRP rope and innovative adhesives. Compos. Struct. 2018; 187, 190-202.

[10] M Frangou, K Pilakoutas and S Dritsos. Structural repair strengthening of RC columns. Constr. Build. Mater. 1995; 9, 259-66.

[11] T Imjai, M Setkit, R Garcia, P Sukontasukkul and S Limkatanyu. Seismic strengthening of low strength concrete columns using high ductile metal strap confinement: A case study of kindergarten school in northern Thailand. Walailak J. Sci. Tech. 2020; 17, 1335-47.

[12] T Imjai, M Setkit, R Garcia and FP Figueiredo. Strengthening of damaged low strength concrete beams using PTMS or NSM techniques. Case Stud. Constr. Mater. 2020; 13, e00403.

[13] R Garcia, I Hajirasouliha, M Guadagnini, Y Helal, Y Jemaa, K Pilakoutas, P Mongabure, C Chrysostomou, N Kyriakides, A Ilki and M Budescu. Full-scale shaking table tests on a substandard RC building repaired and strengthened with Post-Tensioned Metal Straps. J. Earthq. Eng. 2014; 18, 187-213. 
[14] R Garcia, K Pilakoutas, I Hajirasouliha, M Guadagnini, N Kyriakides and MA Ciupala. Seismic retrofitting of RC buildings using CFRP and post-tensioned metal straps: shake table tests. Bull. Earthq. Eng. 2017, 15, 3321-47.

[15] Y Helal, R Garcia, K Pilakoutas, M Guadagnini and I Hajirasouliha. Bond of substandard laps in RC beams retrofitted with post-tensioned metal straps. ACI Struct J. 2016; 113, 1197-208.

[16] CK Ma, R Garcia, SCS Yung, AZ Awang, W Omar and K Pilakoutas. Strengthening of predamaged concrete cylinders using post-tensioned steel straps. Proc. Inst. Civ. Eng. Struct. Build. 2019; 172, 703-11.

[17] T Imjai, U Chaisakulkiet, R Garcia and K Pilakoutas. Strengthening of RC members using PostTensioned Metal Straps: state of the research. Lowl. Tech. Int. 2018; 20, 187-96.

[18] ACI Committee 318. Building Code Requirements for Structural Concrete: (ACI 318-19); and Commentary (ACI 318R-19). American Concrete Institute, Farmington Hills, MI, 2019.

[19] British Standard Institution. BS 1881-116:1983. Testing Concrete - Part 116: Method for Determination of Compressive Strength of Concrete Cubes. BSI, London, UK, 1983.

[20] ASTM C39 / C39M-20, Standard Test Method for Compressive Strength of Cylindrical Concrete Specimens. ASTM International, West Conshohocken, PA, 2020.

[21] ASTM C496 / C496M-17, Standard Test Method for Splitting Tensile Strength of Cylindrical Concrete Specimens, ASTM International, West Conshohocken, PA, 2017.

[22] British Standard Institution. BS 1881-118:1983 Testing Concrete - Part 118: Method for Determination of Flexural Strength. BSI, London, UK, 1983. 